\title{
CHAPTER 2 \\ PERSONNEL INCENTIVES SYSTEM AS AN OBJECT OF MANAGEMENT SOCIOLOGY
}

\subsection{The social essence of the incentive mechanism}

In accordance with the definition of motivation as a set of internal and external driving forces that induce a person to effective and proactive activities in order to meet his needs, set the boundaries and forms of activity and give this activity a focus, focused on achieving certain goals, it can be assumed that labor activity contributes to the actualization and satisfaction of the needs of the individual, bringing the expected result, both for the employee and for the organization.

One of the important elements of purposeful behavior as an individual interaction with the social environment is a person's orientation towards a certain result. Social behavior is an activity that involves some personally significant results and rewards. This reward can be any «good» (knowledge, information, comfort, respect, fame, benevolent attitude, power, money, etc.). And also this is an activity that occurs under the influence of socio-economic factors.

A person, being a socially free individual, consciously enters into labor relations, chooses a type of activity and comes to an organization with certain requirements for it and expects something definite for his behavior. Most of the purposeful human behavior in the organization is the result of conscious decisions, in particular about the amount of effort (contribution) that makes sense to make in your work. This decision is made on the basis of calculation, comparing your contribution with the return of the organization and striving to get the expected result $^{143}$. The results of this comparison can lead to both an increase in labor activity and a decrease in it.

In this sense, behavior directed towards a social result is always a social relation, direct or mediated social interaction, since the individual here deals not only with the social objects (goods) he needs, but also with social subjects - other people, groups, organizations, social institutions - «producing» and controlling these benefits ${ }^{144}$.

This feature of the social interaction between the employee and the organization gives grounds to consider labor activity as a process of social exchange.

Both labor activity and social interaction have a number of common characteristics: this is the result of conscious decisions that result in goal-oriented rational activity, in the process of which the subjects of relations achieve measurable personally significant results and rewards, which actualizes and contributes to the satisfaction of many individual needs.

${ }^{143}$ See: Lawler E.E. Motivation in work organizations. - Belmont: Wadsworth, 1973. - P. 120.

${ }^{144}$ Naumova N.F. Sociological and psychological aspects of purposeful behavior. - M.: Nauka, 1988. -P. 8. 
M.S. Kagan believes that the personality must «be determined not through psychology, and even more so not through physiology, but through its holistically considered activity $\rangle^{145}$. He also proposes to consider personality as a result of socialization of an individual, «in which the latter becomes a subject of activity and it is in this capacity that he joins social experience, disobjectifies it, assimilates and assimilates (to the extent, of course, of his individual capabilities and abilities)». ${ }^{146}$ A.V.Tikhonov emphasizes that «human activity is initially social, it is inseparable from the problems that are social in their genesis and from cooperation with the people involved in their solution... $\rangle^{147}$

At this stage, it becomes necessary to consider the essence (structure) of labor relations (social interaction).

As noted earlier, a person's labor activity is social interaction, since labor behavior aimed at a social result is always a social relation, direct or mediated, since the individual deals not only with the social objects he needs, but also with social subjects - other people, groups, organizations. It is obvious that such social interaction consists of two elements ${ }^{148}$ :

1. the relationship of the individual with the necessary objects, affecting the redistribution of the benefits of the organization;

2. the relationship of the individual with social subjects, affecting the issues of socio-psychological and status-role interactions.

It is logical to assume that human management in an organization should take into account a set of fundamental and situational factors that characterize these two elements and their features in the exchange process.

In theory, almost any set of goals or expectations of an individual can be included in exchange. Researchers have attempted to determine what is exchanged for what, what the organization gives for each type of individual contribution: money - for the time of work; social recognition and safety - for work and loyalty to the organization; the possibility of creative and free labor - for high productivity and quality, for creative efforts to achieve the goals of the organization, etc. ${ }^{149} \mathrm{In}$ studies of role behavior, it is argued that the acceptance of a certain social role depends on how comfortable the individual is with the «desired net balance» of «rewards» and «losses» calculated by him, which can include any personal values and feelings of loneliness. etc. ${ }^{150}$ When using the exchange scheme to assess the «quality of life», it is proposed to consider it as the result of a «deal» between an individual and society about four main «resources» - money, time, relationships

\footnotetext{
${ }^{145}$ Kagan M.S. Human activity. Experience in systems analysis. - M., 1974. - P. 259.

${ }^{146}$ Ibid. - P. 258.

${ }^{147}$ Tikhonov A.V. Sociology of management: theoretical analysis. - SPb.: Publishing house of SPbSU, 2000. - P. 120.

${ }^{148}$ See: Naumova N.F. Ibid. - P. 8.

${ }^{149}$ Schein E. Organizational psychology. - N. Y.: Wiley, 1965. - P. 65.

${ }^{150}$ Schoenherr R., Greeley A. Role commitment processes and the American catholic priesthood // Amer. Sociol. Rev. 1974. Vol. 39. № 3. - P. 407-426.
} 
and skills ${ }^{151}$.

In Western models of social exchange, the relationship between man and the social environment was based solely on the concept of «economic man», substantiated in the 18 th century. A. Smith. So, G. Homans built the mechanism of social exchange on the assumption that it is the direct mutual usefulness of people, the exchange of rewards that is the source, the guarantor of social solidarity and orderliness of society. The mechanisms by which this exchange operates, according to Homans, are quite simple ${ }^{152}$. For example, if there was a situation in the past in which a person's behavior was rewarded, then the more the current situation resembles the past, the more likely the person will behave in the same or similar way. Or: the more often, during a given time period, one person's behavior rewards another's behavior, the more often that other will behave in the same way. Moreover, the more valuable to a person the behavior that is rewarded by another, the more often he will demonstrate rewarded behavior.

The reasons and incentives that would induce the employee to work, that is, contribute to the emergence of purposeful labor behavior (according to G. Homans), ${ }^{153}$ can be represented in the form of five points:

1. "Statement of success». The more often an activity is rewarded, the more likely it is to be done. Behavior that has positive consequences for the individual is very likely to repeat itself. And, therefore, it becomes possible to stimulate those performance results that are most important for the organization.

2. «Statement of incentive». Similar circumstances or similar situations will stimulate behavior that has been rewarded in similar situations in the past. This makes it possible to predict the necessary behavioral reactions to innovations and helps to expand the influence on the employee.

3. «Statement of value». The more valuable the results of an action are to an individual, the more likely it is that the action will be performed. Here we are talking about the need to organize the work process in such a way, in which the employee would not only receive monetary rewards, but would also feel the significance of their activities.

4. «Statement of deprivation - satiety». The more often a person receives a specific reward for an action, the less valuable the additional element of that reward is. Thus, some rewards become less effective, which means that incentives to work, even for the same positive action, should not be constant for a long time. True, this is less true for rewards where saturation is less likely to occur (eg, money).

5. «Statement of emotionality». It is about the conditions in which people react emotionally to various rewarding situations. This provision covers two types of reactions. People who are not getting what they expected are expected to become

${ }^{151}$ Gerson E. On «quality of life» // Ibid. 1976. - Vol. 41. - № 5. - P. 793-806.

${ }^{152}$ Homans G. Social behavior: its elementary forms. - N.Y.: Harcourt, Brace, 1961. - P. 53-75.

${ }^{153}$ See: Homans G. The Human Group. - N.Y.: Harcourt, Brace and Co. 1950., Homans G. Social Behavior as Exchange. - N.Y.: Harcourt, 1974. 
angry and aggressive, which is not conducive to quality of work. Moreover, such workers can turn against the organization of their colleagues by spreading negative information. People who receive more or as much as they expected will be happy and behave positively, thereby "telling" the organization that they value it and are ready to continue working in it.

The fundamental limitation of this scheme lies in the fact that it does not take into account practically any actually social mechanism for regulating behavior (role, institutional, normative, associated with power, etc.).

Another, normative interpretation of "exchange" can be found in the critical clarifications of A. Gouldener ${ }^{154}$ :

1. Compliance with the norm is usually rewarded. (Gouldener's clarification: conformity is a function of rewarding it on the part of another - a person, a group, etc. - and the «price» of this conformity for the one who follows it).

2. The more the behavior corresponds to the norm (the expectations of others), the more it is rewarded by these others. (Clarification: the longer the conformal actions are performed, the less they are valued and rewarded. This can have two consequences: a) a person decreases his conformity and does not receive a reward, the exchange is disturbed; b) a person increases his conformity so that the reward does not decrease (conformity inflation).

3. Scarcity or level of remuneration does not affect the stability of the social system as long as participants accept existing norms. (Clarification: when participants in an interaction accept certain norms, adherence to them is considered mandatory and therefore less rewarded. Thus, having common norms increases the likelihood that conformity will be rewarded, but reduces the amount of reward (the paradox of conformity).

4. Acceptance of existing norms leads to the complementarity of rights and obligations, that is, one participant in social interaction does not expect more reward than the other can and wants to give. (Clarification: the equilibrium of a social system is not determined by complementarity, but by the degree of reciprocity of reward. The more one-way exchange becomes, the more unstable the relationship becomes. Reciprocity implies that not only the rights of one party are obligations of the other, but that each party has rights and obligations).

The above approaches to explaining the action of social exchange do not show that people in the process of their professional activities are able to be guided not only by their own interests, «but they can also be guided by other aspirations altruism, a sense of justice, conformity to status, etc..${ }^{155}$. Thus, the emergence of another «motivation» that does not fall into the «exchange» scheme can be regarded as a manifestation of other mechanisms of social interaction. This is a motivation that is not based solely on the rational expectation of the individual.

\footnotetext{
${ }^{154}$ See: Gouldener A. The coming crisis of western sociology. - N.Y.: Basic Books, 1970. - P. 231241.

${ }^{155}$ Michener H., Cohen E., Sorensen A. Social exchange: predicting transactional outcomes in fiveevent, four-person systems // Amer. Sociol. Rev. - 1977. - Vol. 42. - № 3. - P. 534. 
Incentives that cannot be explained only by mutual benefits and rewards are realized through the following social mechanisms ${ }^{156}$ :

Internal reward mechanism. Reward of this type does not come from the social environment: the individual, in a sense, "gives out to himself», the environment can neither directly give nor take away this reward. This type of reward can be attributed to the so-called psychological return that a person receives from the work process itself (a sense of the social necessity of his work, a sense of success, the ability to do what he has dreamed of for a long time, etc.) The process of internal reward can be represented as a chain «return - social reward - inner experience of reward». Obviously, this group includes any positive psychological state caused by any reward (for example, wages). Internal reward mechanism is a kind of internal motivation that lies in the work itself, in its meaning and value. Internal motives are associated with social significance, the satisfaction that work gives due to the fact that it contains the opportunity for self-development, creativity, the opportunity to be useful. This is the motivation that is contained in the sense of work, its purpose. This type of motive includes:

- self-affirmation;

- conviction in the importance of the chosen type of activity;

- need for communication;

- a dream to work in a certain specialty;

- a sense of pride and patriotism for their work;

- a sense of the need for the chosen profession.

External reward mechanism. The only difference from internal reward is that in the chain of «external» reward, the first two elements are considered sufficient. The organization can and should guarantee this type of remuneration to its employees. These are wages, social security, opportunities for professional growth, labor safety, etc. This is the type of reward that, to a certain extent, comes from outside, from the side of the organization and is external motivation, that is, it contains those motives that relate to the content of labor and its characteristics. It:

- wage;

- social benefits;

- possibility of career growth;

- the ability to buy prestigious items;

- obtaining the desired life status;

- satisfaction with occupational safety, etc.

"Internal» reward appears where it (and thus the exchange) cannot be guaranteed. An organization, for example, can provide an employee with equipment, information, interesting tasks, but it cannot believe that it rewards him with creative satisfaction, because it cannot guarantee it. In any (especially good) conditions, this satisfaction will not be received by an employee who is incapable and (or) not motivated by creativity itself. And even where creative satisfaction

${ }^{156}$ Naumova N.F. Ibid. - P. 13-15. 
$\overline{\text { does take place, it is not organizationally guaranteed. A person will not receive }}$ spiritual satisfaction from his work if the work is not desired and loved for him.

Failure to guarantee exchange should be considered when designing incentive systems. This means that the more the employee is aware of the "guaranteed exchange», the more efficiently he will work. But even in this case, not everything is so simple. Indeed, the exchange as such can be guaranteed, but it is impossible to guarantee the employee that the exchange will be equivalent, that is, it will adequately reflect the individual contribution of each participant to the labor process and provide him with what he needs ${ }^{157}$. The equivalence probability reflects the mechanism of nonequivalent exchange. This mechanism, from the point of view of its significance for stimulating labor, is characterized by the impossibility of directly determining at a specific moment the degree of exchange equivalence. There are three reasons for this impossibility.

(1) it expresses the quality of human existence. Here we are talking about the fact that it is impossible to establish and rank in the same way for all participants in the exchange of values, and to establish a single hierarchy, since the social values of each person are individual and represent a different degree of significance for the individual. We are talking about the system of expectations of a person in relation to the benefits received from the organization, which is associated with the idea of the quality of life and the level of social relationships.

(2) an increase in the number of "collective» ${ }^{158}$ types of work. The deepening of the social and technical division of labor contributed to the emergence of new social functions and such labor, in relation to which it is very difficult to determine what, in fact, is its immediate result (for example, the work of a doctor). That is why some organizations began to replace the assessment of the performance of an employee with an assessment of his behavior in the organization - discipline, diligence, loyalty, etc. Thus, determining the degree of equivalence of the exchange of labor results is complicated by the variety of emerging criteria for assessing not only the immediate result, but also the labor process itself ... This requires a clear systematization and coordination of the «criterion apparatus» of the employee and the organization.

(3) exchange equivalents are far from universal in time. What was valuable to the employee yesterday may not be of value today, since his motives and needs can be transformed under the influence of the external environment and personal attitudes. We can agree with the statement that the motivational sphere of a person is dynamic, formed on the basis of situational factors and is realized at a specific point in time. At the same time, the characteristic of the stability of the motivational sphere depends on the subjective emotional experience of reality and physical characteristics (reaction speed, etc.).

In this regard, it should be noted that any individual strives in the process of

${ }^{157}$ See: Volkovitckaia G.A. Labor incentives: quality criteria. // Bulletin of the Herzen Russian State Pedagogical University. №8 (27): Postgraduate notebooks: Scientific journal. - SPb., 2007. - 29-38. ${ }^{158}$ See: Naumova N.F. Ibid. - P. 15. 
$\overline{\text { his social relations in general, and in the process of his labor activity in particular, }}$ to achieve a position in which the level of exchange equivalence for him would be maximum. The guarantee of the equivalence of remuneration to the results of labor is the key to the success of stimulating the labor activity of the employee. This fact must be taken into account when designing and building a personnel incentive system.

The main provisions of the concept of social exchange make it possible to single out the basic elements that determine the efficiency of labor activity and determine the possibility of creating an equivalent exchange. These include ${ }^{159}$ :

- the system of expectations of the employee in relation to the benefits received from the organization, based on ideas about the quality of life, the level of social relationships, on the one hand, and the system of expectations of the organization in relation to the performance and nature of the employee's work, on the other;

- the system of criteria for assessing the immediate result and the labor process by the employee and the organization;

- the motivational structure of the personality, which is formed on the basis of the psychophysiological characteristics of the employee, situational factors, which is realized at a particular moment in time.

The parameters for assessing the level of equivalence of social exchange between participants in labor relations are:

1. the level of consistency of the elements of the system of expectations of the employee and the organization;

2. the level of validity of the criteria for assessing the results of labor activity;

3. the level of comparability of the characteristics of the motivational structure of the personality with the characteristics of the stimulating effect.

To summarize, the following can be summarized:

Human labor activity is a social voluntary interaction aimed at results; it is based on social exchange and guarantees the participants in the labor relationship a certain level of mutual benefit. The mechanism of social exchange involves motivation to participate. Thus, a high-quality incentive system should guarantee the equivalence of social exchange, the awareness of which optimizes the labor activity of workers.

The criteria for assessing the effectiveness of the process of stimulating labor activity is the level of equivalence of social exchange between participants in labor relations.

\subsection{Social qualities of the personnel incentive system}

Having defined the human labor activity as social interaction based on social exchange, which guarantees the participants in labor relations a certain level of mutual usefulness, it can be argued that the mechanism of social exchange

\footnotetext{
${ }^{159}$ See: Volkovitckaia G.A. Management and stimulation of labor. // Management of the XXI century: education and business. - SPb.: LLC «Book House», 2007. - P. 123.
} 
presupposes motivation to participate. That is, in order to involve an individual in activities, in work, it is necessary to interest him, that is, to kind of stimulate this interest. Since the object of managerial influence is a person, a creature by its nature is social, then in order to achieve the greatest efficiency of managerial influences, it is necessary to endow the incentive system with social qualities that characterize the potential for achieving social results and development. A person works in a team, and in the event of alienation from him, incentives to work may be lost. In this regard, the incentive system and the incentives themselves can be individually oriented or group oriented, but must always be socially oriented.

As it was revealed earlier, a person in his labor activity is driven not only by material interest, but also by a number of other stimulating factors, such as love for work, passion for the profession, etc. All this allows us to assert that the construction of the entire incentive system in the organization should take place on the so-called «social» basis, i.e. so as not only to elementarily satisfy the urgent needs of the employee and provide him with the opportunity to continue to exist (albeit comfortable), but also to contribute to the development of his personality, instill pride in his work, as well as ensure the stability of the organization and contribute to its further growth and expansion.

Such a new incentive system that meets the above requirements will be the system that possesses «sociality» or, in other words, social qualities, ensuring the implementation of the social goal of the personnel management system, that is, the achievement of a given degree of social needs of workers.

In this consideration, the social qualities of the incentive system are as follows:

1. Freedom of choice by the individual of the incentive system. Since in the process of labor activity an individual interacts with social subjects, the fundamental element of such interaction is the right to freely enter into such interactions, the right to choose activities in the organization that most fully meets the requirements of the employee and his expectations. This quality stems from the requirements for the legality of the construction of incentive systems, which should be based on the Labor Code of the Russian Federation and other regulatory legal acts.

This quality follows from the Constitution of the Russian Federation, the corresponding provision of which states that labor is free. Everyone has the right to freely dispose of their abilities for work, to choose their type of activity and profession. Every person «has the right to work in conditions that meet the requirements of safety and hygiene, to remuneration for work without any discrimination and not lower than the minimum wage established by federal law, as well as the right to protection from unemployment» ${ }^{160}$.

2. Providing employees with personally significant results (social and material benefits). Providing an employee with the benefits that he really needs is the first step towards building a high-quality socially-oriented incentive system,

${ }^{160}$ See: Constitution of the Russian Federation. - Art. 37. 
since personal interest is the main argument in favor of working in a particular company.

Here it is necessary to take into account that the motivational sphere of the personality is dynamic, formed in a specific period of time. Therefore, in order to reward an individual with personally significant results, an analysis of his individual characteristics is necessary. These features include characteristics such as marital status, gender, age, etc. This approach is also necessary when managing the business career of personnel, since with age and the development of professional skills, both the goals and needs of the employee change.

3. Social protection of personnel. It is aimed at monitoring compliance with the legislation in force in the Russian Federation and ensuring social guarantees for employees, such as annual paid leave, paid sick leave, etc. Social guarantees are a mechanism of long-term action, the obligations of the state provided for by law, aimed at observing and realizing the constitutional rights of citizens. The basis of state social guarantees is the minimum social guarantees, such as wages, pensions, health care, etc.

The direct role of organizations in the social protection of personnel is reduced to compliance with the minimum wage, making contributions to pension and health insurance for workers.

The provision of social guarantees allows us to talk about the social attractiveness of the enterprise for the personnel. Here, the social development of the organization also plays an important role ${ }^{161}$, where the main social guidelines of management are:

- creation of favorable conditions for work and rest of the employees of the organization;

- $\quad$ remuneration for work;

- $\quad$ social protection of personnel;

- maintaining an optimal moral and psychological atmosphere in the team.

4. Interdependence of the employee's contribution and the remuneration he receives. This quality presupposes the presence of a labor rate setting service, study and calculation of working hours, etc. Due to the presence of clear positions in the field of remuneration and bonuses, it is possible to achieve an increase in labor productivity in organizations without the introduction of any other technologies, since it is precisely «confidence in the future» that is very often one of the main stimulating factors of work in a particular organization.

One of the ways to assess the employee's contribution to the organizational process is the method for determining the weight of the position (position assessment). With this approach, the following characteristics of the position are assessed in a complex:

- knowledge and skills necessary to perform production functions, including interpersonal communication skills;

${ }^{161}$ Kuznetsov A.L., Zakharov N.L. Ibid. - P. 149. 
- the ability to solve production issues and make competent decisions, including the frequency of occurrence of problem situations;

- the size of official assignments and responsibilities assigned to this official unit.

5. The reciprocity of the interests of the organization and the employee, which implies a mutually interested relationship between the organization and the personnel, as a result of which long-term cooperation is ensured.

Long-term cooperation between the organization and the staff, i.e., in other words, a decrease in staff turnover can be achieved by focusing on the concept of the quality of working life $e^{162}(\mathrm{QWL})$, the essence of which is to improve labor motivation, to ensure the diversity and enrichment of the content of labor, the full use of the intellectual, creative and mental potential of the employee. The QWL system includes a set of values:

- self-actualization in professional activity, in which the organization creates such conditions for the employee to develop and use all his abilities;

- growth prospects - maintaining the employee's confidence in a work that is favorable for him;

- remuneration for work in order to maintain motivation at the required level of the organization;

- $\quad$ safety - ensuring safe working conditions;

- moral and psychological atmosphere;

- work optimality - work is not an obstacle to leisure and recreation, personal growth and family relations, but by its results and focus should contribute to the development of these components.

6. Streamlining the choice of business contacts, in which the employee is given the opportunity to substantiate the advisability of involving a certain circle of employees in labor activities to perform production tasks. This quality refers to the psychological relationships within the team. The importance and necessity of assessing the level of harmony of intra-organizational relations has long been known and proven by researchers.

The method for assessing psychological relationships is the sociometric technique developed by $\mathrm{J}$. Moreno ${ }^{163}$, which is used to diagnose interpersonal and intergroup relationships in order to change, improve and improve them. With the help of sociometry, it is possible to study the typology of social behavior of people in the conditions of group activity, to judge the socio-psychological compatibility of members of specific groups.

The sociometric procedure ${ }^{164}$ can have several purposes of carrying out:

\footnotetext{
${ }^{162}$ Ibid. - P. 89.

${ }^{163}$ See: Moreno. J.L. Sociometry. Experimental method in the science of society / Trans. from English - M.: Academic project, 2004.

${ }^{164}$ See: Methods of psychological diagnostics. - M., 1993, Methods of social and psychological diagnostics of a person and a group. - M., 1990.
} 
a) measuring the degree of cohesion-disunity in the group;

b) identifying «sociometric positions», that is, the relative authority of the group members on the basis of sympathy-antipathy, where the «leader» of the group and the «rejected» find themselves at the extreme poles;

c) detection of intragroup subsystems, cohesive formations, which may be headed by their own informal leaders.

The use of sociometry makes it possible to measure the authority of formal and informal leaders for regrouping people in teams so as to reduce tensions in the team arising from the mutual hostility of some members of the group. The sociometric technique is carried out by a group method, its implementation does not require much time (up to 15 minutes). It is very useful in applied research, especially in work to improve team relationships.

During the sociometric procedure, participants may be asked the following types of questions:

Questions to study business relationships:

- Who would you go on a long business trip with?

- Which of your colleagues would you turn to for help in a business matter first?

- Who do you consider worthy to serve as a leader?

Questions to explore personal relationships:

- Which of your colleagues would you turn to for help in resolving a difficult life situation in the first place?

- Which of your colleagues would you never ask for advice?

- Which of your colleagues would you like to invite to your birthday? etc.

Such a «social» approach to labor incentives will avoid such a negative phenomenon as alienation ${ }^{165}$. For Karl Marx, alienation is the loss of the meaning of existence by the workers in the labor process in the era of capitalism, it is the process of separating the process and the results of their activities from people. Most 21st century thinkers are skeptical about the ability to overcome alienation completely. Many see the main task in helping a person intellectually and morally to live with dignity in modern society, to feel dignified in the workplace. And the stimulation of labor activity as a way of managing a person in an organization should be subordinated to this task.

\footnotetext{
${ }^{165}$ See: Lapin N.I. Total alienation and general crisis of early socialism. // Bulletin of the Academy
} of Sciences of the USSR, 1990. - No. 5 . 